\title{
Voleybol Antrenörlerinin Mesleki Öz Yeterlik Düzeylerininin Bazı Demografik Özelliklere Göre İncelenmesi
}

Pero Duygu DUMANGÖZ1 ${ }^{1}$, Ramazan SANLAV ${ }^{2}$

ORIJIINAL ARAŞTIRMA

${ }^{1}$ İstanbul Teknik
Üniversitesi, Beden
Eğitimi Bölümü
İstanbul/Türkiye
2'̇̇stanbul Medipol
Üniversitesi, Sosyal
Bilimler Meslek
Yüksekokulu Spor
Yönetimi Programı
İstanbul/Türkiye

Sorumlu Yazar:

Pero Duygu

DUMANGÖZ

Orcid ID: 0000-

0002-2827-5538

\section{Yayın Bilgisi}

Gönderi Tarihi:

24.06.2021

Kabul Tarihi:

26.08.2021

Online Yayın Tarihi: 28.08.2021

Doi:

10.38021/asbid.956931

\begin{abstract}
$\ddot{O} z$
$\mathrm{Bu}$ araştırmanın amacı voleybol antrenörlerinin mesleki öz yeterlik düzeylerinin bazı demografik özelliklere göre farklılaşıp farklılaşmadığını belirlemektir. Araştırma konusu, nicel araştırma yöntemlerinden, betimleyici araştırma deseninde incelenmiştir. Araştırma kapsamında ulaşılabilen 120 voleybol antrenörünün (34 kadın $(\% 28,3)$ ve 86 erkek $(\% 71,7)$ mesleki öz yeterlik düzeylerinin belirlenmesi amacıyla Koçak ve Güven (2018) tarafından geliştirilen Voleybol Antrenörü Mesleki Öz Yeterlik Ölçeği (VAMYÖ) kullanılmıștır. Ayrıca demografik özelliklerin belirlenmesine yönelik araștırmacılar tarafından oluşturulan kişisel bilgi formu kullanılmıştır. Uygulamaya geçilmeden önce VAMYÖ’ nün kullanımına ilişkin izin, ilgili bilim insanlarından yazılı olarak alınmıştır. Araştırmaya başlamadan önce etik kurul raporu alınmıştır. Ölçekler, elektronik ortamda hazırlanarak, sosyal medya ve/veya e-mail iletişim kanalları vasıtasıyla ulaşılabilen voleybol antrenörlerine iletilmiştir. Verilerin analizi için SPSS 20.0 paket programı kullanılmıştır. Çalışmada yer alan kategorik veriler frekans ve yüzde ile sürekli veriler ortalama ve standart sapma ile ifade edildi. Veriler normal dağılım açısından Kolmogorov-Smirnov ve dağılım grafikleri ile incelendi. Sürekli verilerin iki grup arasında karşılaştırılmasında Mann-Whitney U testi, ikiden fazla grubun karşılaştırılmasında Kruskal-Wallis testi kullanıldı. Post-hoc analizler Bonferroni düzeltmesi kullanılarak Mann-Whitney U testi ile yapıldı. Hata payı 0,05 plarak kabul edilmiștir. Sonuç olarak, voleybol antrenörlerinin mesleki öz yeterlik ölçeği toplam puanlarında antrenörlük kademesine göre anlamlı bir fark ortaya çıktı̆̆1; cinsiyet, yaş, eğitim düzeyi, antrenör belgesi edinme yolu, antrenörlük deneyimi ve mesleki durumu değişkenlerine göre ise anlamlı bir fark olmadığı görülmüştür. Antrenörlerin öz yeterlik algılarının incelenmesi, onların daha fazla yeterliğe sahip olmalarına inanmalarını ve dolayısıyla daha fazla mesleki eğitime ihtiyaçları olabileceğini anlamalarına izin verir. Ayrıca bu konuda yapılan çalışmalar hem başarılı sporcular yetiştirmek hem de antrenör eğitim programları geliştirmek için faydalı bilgiler sağlar.
\end{abstract}

Anahtar kelimeler: Antrenör, Voleybol, Antrenörlük Eğitimi, Öz-Yeterlik

\section{Investigation of the Professional Self-Efficiency Levels of Volleyball Coaches According to Some Demographic Characteristics}

\begin{abstract}
The aim of this research is to determine whether the professional self-efficacy levels of volleyball coaches differ according to some demographic characteristics. The research subject was examined in the descriptive research design, one of the quantitative research methods. The Volleyball Coach Professiyonal Self-Efficacy Scale (VAMYÖ) developed by Koçak and Güven (2018) was used to determine the professional self-efficacy levels of 120 volleyball coaches (34 female $(28.3 \%)$ and 86 male $(\% 71.7)$ ) who could be reached within the scope of the research. The personal information form created by the researchers was used to determine the characteristics. Before the application, the permission for the use of VAMYÖ was obtained in writing from the relevant scientists. The ethics committee report was obtained before starting the research. The scales were prepared in electronic environment, social media and/or e-mail. It was communicated to the volleyball coaches who could be reached through communication channels. The SPSS 20.0 package program was used for the analysis of the data. The categorical data in the study were expressed as frequency and percentage, and the continuous data were expressed as the mean and standard deviation. The data were analyzed in terms of normal distribution with Kolmogorov Smirnov and distribution charts. The Mann-Whitney U test was used to compare the attached data between two groups, and the Kruskal-Wallis test was used to compare more than two groups. Post-hoc analyzes were performed with the Mann Whitney U test using Bonferroni correction. The margin of error was accepted as 0.05 . As a result, there was a significant difference in the total scores of the professional self-efficacy scale of volleyball coaches according to the level of coaching; It was seen that there was no significant difference in terms of gender, age, education level, way of obtaining a trainer's certificate, coaching experience and professional status. Examining trainers' perceptions of selfefficacy allows them to believe that they have more competence and therefore understand that they may need more vocational training. In addition, studies on this subject provide useful information for both raising successful athletes and developing coach training programs.
\end{abstract}

Keywords: Coach, Volleyball, Coach Education, Self-Efficacy 


\section{Giriş}

Spor bağlamında, spora hizmet edenlerin bireysel ve grup davranışlarının incelenmesi önemli ve bilgilendirici bir çabadır. Ancak çok az çalışma voleybol antrenörlerin kendi rollerini yerine getirmedeki öz yeterlik inançlarını araştırmıştır. Öz yeterlik, Bandura' nın sosyal bilişsel teorisinin temel kavramıdır. Bandura (1986)' ya göre öz yeterlik inancı “insanların belirli performans türlerini elde etmek için gerekli olan eylem planlarını, organize etme ve uygulama yeteneklerine ilişkin algılarıdır." Mesleki yeterlik kavramı, meslek dalının gerektirdiği görevlerin yerine getirilmesi için gereken mesleki bilgi, beceri ve tutumlara sahip olma durumu olarak tanımlanmaktadır (Koçak ve Güven, 2018). İnsanların yapmayı istedikleri ya da yapmakta oldukları meslekler, kişiliklerinin bir yansımasıdır (Holland, 1997; akt. Koçak ve Güven, 2018). Antrenör yeterliği ise,” antrenörlerin sporcularının öğrenme ve performansını etkileme kapasitesine sahip olduklarına ne ölçüde inandıkları" şeklinde açıklanır (Feltz, Chase, Moritz ve Sullivan, 1999).

Öz yeterlik bir bireyin bir görevi yerine getirme kabiliyetine ne kadar güvendiğini ifade ettiğinden, kendine güven ile yakından ilişkilidir (akt. Papastergiou, 2010). Kişinin ne kadar çaba sarf edeceğini ve engellerle karşılaştığında göreve ne kadar devam edeceğini, öz yeterlik inancı belirler (Mesquita, Borges, Rosado, and Batista, 2012).

Öz yeterlik teorisi, bilişsel, motivasyonel, duygusal ve işlevsel süreçlerin kişisel inançlar tarafından kontrol edildiğini ve yönetildiğini öne sürer. Uluslararası araştırmaların yanı sıra farklı analitik ve metodolojik stratejilerle elde edilen kanıtlar, yüksek düzeyde öz yeterliğin olumlu duygu ve düşünceler, benlik saygısı, daha yüksek hedefler ve yüksek motivasyon ile pozitif yönde ilişkili olduğunu göstermiştir (Tojjari, Esmaelli and Bavandpour, 2013). Bu açılardan değerlendirilecek olursa antrenörlerin mesleki öz yeterlik inaçlarının önemi daha da belirginleşmektedir.

Antrenör yeterlikleri, son araştırmalar ve uluslararası eğitim programları tarafından da teyit edildiği üzere temel olarak eğitim, yarışma ve yönetim alanlarına ayrılmıştır (Duffy, 2008; Demers, Woodburn, Savard et al. 2006; Mesquita vd., 2012). Ayrıca antrenörlük dinamik ve sürekli gelişen bir meslek olduğundan antrenörlük etkinliğini artırmak için yeni yetkinlikler kazanmak önemlidir. $\mathrm{Bu}$ nedenle antrenörlerin iletişim kurma, sorumluluk alma, öğrenme gibi becerilerini temsil eden sosyal ve kişisel yeterlikleri, gerek sporcularıyla gerekse spor çevreleriyle etkileşimlerinin temelini oluşturur. Bu yeterliklerin antrenöre kazandırılması ya da artırılması aşamasında antrenör eğitim programlarının hazırlayıcılarına da önemli görevler düşmektedir.

Uzun yıllardan beridir oynanan voleybol, dinamik, farklı pozisyonlarla, farklı oyun varvasyonlarını içeren, çok boyutlu sportif becerilere ihtiyaç duyulan bir takım oyunudur (Wulf, 2007; akt. Koçak ve Güven, 2018). Voleybol antrenörlerininde voleybol sporunun dinamik yapısına uyum sağlayacak sportif becerilerini geliştirmesinin yanı sıra sosyal becerilerini de geliştirmesi, uzmanlık gerektiren bir çok konuda sorumluluk alması gerekir. 
Bir bireyin öz yeterliği, dış deneyimlerinden ve birçok koşulun sonucuna ilişkin kişinin kendi algısından etkilenir. Aynı zamanda bireyin motivasyonu ve başarısı üzerinde de önemli bir etkiye sahiptir. Birçok çalışma, öz yeterlik inançlarının bağlamsal ve göreve özgü olduğuna işaret eder (Bandura, 2012; Klassen, Tze, Betts and Gordon, 2011). Bandura (1997)’ ye göre öz yeterlik inançları dört farklı yoldan kazanılan bilişsel bir süreçtir:

Etkin uzmanlık deneyimi: Benzer görevleri yerine getirmekten kazanılan deneyim

Dolaylı yoldan deneyim: Başkalarını gözlemleyerek kazanılan deneyim

Sosyal ikna: Diğer kişilerin bir görevi yerine getirme yeteneklerine ilişkin algıları

Fizyolojik ve psikolojik durumlar: Bireyin bir görevi yerine getirirkenki fiziksel ve ruhsal durumu.

Bunlardan en etkili olanı etkin uzmanlık deneyimidir (Pajares, 2002; Usher ve Pajares, 2009).

Güçlü öz yeterlik algısına sahip insanlar, hayatlarındaki olayların sonuçlarını etkili bir şekilde kontrol edebileceklerine inanırlar. Bu algı, onlara öz yeterlik duygusu zayıf olanlardan farklı bir bakış açısı verir. Çünkü bu duygu, davranışları üzerinde doğrudan bir etkiye sahiptir. Bu nedenle, öz yeterlik yaşam boyunca başarı ve başarısızlıkta çok önemli bir faktör olabilir (Luszczynska, Gutierrez-Dona and Schwarzer, 2005). Öz yeterlik teorisi, kişinin kendi yeteneklerine olan inancının, onu istenen sonuçlara ulaşmak için gerekli davranışlara götürdüğünü ileri sürmekte ve onu ek çaba göstermeye teşvik etmektedir (Tojjari vd., 2013).

Antrenörlerin yeterlikleri üzerine yapılan araştırmalarda ortaya çıkan sonuçlar, takım sporcularına yüksek yeterlik inançlarını yansıtan antrenörlerin takımlarının, daha etkili hale geldiğini ve performanslarının arttığını göstermektedir (Hoyt, Murphy, Halverson and Watson, 2003). Sporda başarılı bir grafik çizmek için antrenörlerin verimliliğini artırmaya yönelik eğitimler ve stratejiler belirlenmelidir.

Voleybol ülkemizde en çok sevilen ve takip edilen spor branşlarından biridir. Profesyonel olarak kapalı salonda ve plajda oynanabilen voleybol, halk arasında bahçede, avluda bile oynanabilen eğlenceli bir oyundur. Bu kadar rağbet gören voleybol sporunun daha fazla nitelik kazanması ve alandaki başarının artması için voleybola hizmet eden kişilerin yüksek standartlarda eğitilmesi ve bu konuda desteklenmesi gerekmektedir. Bu kişilerin başında takım liderleri olan antrenörler konumlanmaktadır.

Bu nedenle, antrenörlerin öz yeterlik algılarının incelenmesi, onların daha fazla yeterliğe sahip olmalarına inanmalarını ve dolayısıyla daha fazla mesleki eğitime ihtiyaçları olabileceğini anlamalarına izin verir. Ayrıca bu konuda yapılan çalışmalar antrenör eğitim programları geliştirmek için faydalı bilgiler sağlar.

$\mathrm{Bu}$ araştırmanın amacı voleybol antrenörlerinin mesleki öz yeterlik düzeylerinin bazı demografik özelliklere göre farklılaşıp farklılaşmadığını belirlemektir. Araştırmanın bağımsız 
değişkenleri cinsiyet, yaş, eğitim durumu, antrenörlük kademesi, antrenörlük belgesi edinme yolu antrenörlük deneyimi ve mesleki durumdur. Bağımlı değişkeni ise, mesleki öz yeterlik düzeyleridir. Araştırma kapsamında oluşturulan ve test edilecek hipotezler şunlardır;

H1: Voleybol Antrenörlerinin cinsiyet değişkeni ile mesleki öz yeterlik düzeyleri arasında fark vardır.

H2: Voleybol Antrenörlerinin yaş durumu değişkeni ile mesleki öz yeterlik düzeyleri arasında fark vardir.

H3: Voleybol Antrenörlerinin eğitim durumu değişkeni ile mesleki öz yeterlik düzeyleri arasında fark vardir.

H4: Voleybol Antrenörlerinin antrenörlük kademesi değişkeni ile mesleki öz yeterlik düzeyleri arasında fark vardır.

H5: Voleybol Antrenörlerinin antrenörlük belgesi edinme yolu değişkeni ile mesleki öz yeterlik düzeyleri arasında fark vardır.

H6: Voleybol Antrenörlerinin antrenörlük deneyimi değişkeni ile mesleki öz yeterlik düzeyleri arasında fark vardır.

H7: Voleybol Antrenörlerinin mesleki durum değişkeni ile mesleki öz yeterlik düzeyleri arasında fark vardir.

\section{Yöntem}

\section{Araştırmanın Modeli}

Araştırma konusu nicel araştırma yöntemlerinden, betimleyici araştırma deseninde incelenmiştir. Bu araştırma ile voleybol antrenörlerinin mesleki öz yeterlik düzeyleri tespit edilmiş ve öz yeterliklerinin bazı demografik özelliklere göre farklılaşma durumları ortaya konulmuştur.

\section{Araştırma Grubu}

Araştırmanın evrenini Türkiye Voleybol Federasyonu' nun belirlediği kriterleri karşılayarak, resmi antrenörlük belgesine sahip olan voleybol antrenörleri oluşturmaktadır. Örneklem grubunu ise araştırma evreni içerisinden araştırmacıların ulaşabildiği, yaşları 20 ile 49 arasında değişen 120 (34 kadın ile 86 erkek) voleybol antrenörleri oluşturmuştur. Katılımcılar rastgele örnekleme yolu ile seçilmiştir.

\section{Veri Toplama Araçları}

Araştırmanın amacı doğrultusunda kullanılan form iki bölümden oluşmaktadır.

1. Kișisel Bilgi Formu 
$\mathrm{Bu}$ form demografik verilerin (Ör. cinsiyet, yaş) ortaya çıkması amacıyla araştırmacılar tarafından oluşturulmuştur. 7 maddeden oluşmaktadır.

2. Voleybol Antrenörü Mesleki Öz Yeterlik Ölçeği (VAMYÖ) (Koçak ve Güven, 2018)

Voleybol antrenörlerinin mesleki öz yeterlik düzeylerini ölçmek üzere, 29 maddelik, likert tipi (1=Kesinlikle katılmıyorum, 5= Tamamen katılıyorum) bir ölçek olan Voleybol Antrenörü Mesleki Öz Yeterlik Ölçeği (VAMYÖ) kullanılmıştır. Ölçek kullanılmadan önce, ölçeği geliştiren bilim insanından yazılı onayı alınmıştır. Ölçek, motivasyon yeterliği, teknik öğretim yeterliği, kişilik kazandırma yeterliği, liderlik ve takım yönetimi liderliği, kondisyon ve taktik yeterliği olmak üzere 5 alt boyuttan oluşmaktadır. Ölçek maddeleri, tamamen katılıyorum=5 puan, çok katılıyorum 4 puan, orta düzeyde katılıyorum=3 puan, az katılıyorum:2 puan ve hiç katılmıyorum=1 puan şeklinde puanlanmaktadır. Koçak ve Güven (2018), yapmış oldukları geçerlik ve güvenirlik çalışması sonucunda alt boyutlara ait Cronbach alfa katsayılarını motivasyon yeterliği, .89; teknik öğretim yeterliği, .89; kişilik kazandırma yeterliği, .85; liderlik ve takım yönetimi yeterliği, .81; kondisyon ve taktik yeterliği, 90 olarak bulmuştur. Bu çalışmada ölçek toplamı için Cronbach alpha güvenirlik katsayısı .84 olarak bulunmuştur.

\section{Verilerin Toplanması ve Analizi}

Araştırma için, İstanbul Medipol Üniversitesi tarafından 16.06.2021 tarihinde ve 58 no'lu kararı ile etik kurul onayı verilmiştir. Ölçekler, elektronik ortamda hazırlanarak, sanal ağ kanalları (sosyal medya, e-mail) vasıtasıyla ulaşılabilen voleybol antrenörlerine iletilmiştir.

Araştırmanın bağımsız değişkenleri cinsiyet, yaş durumu, eğitim durumu, antrenörlük kademesi, antrenörlük belgesi edinme yolu, antrenörlük deneyimi ve mesleki durumdur. Bağımlı değişkeni ise mesleki öz yeterlik düzeyleridir.

Çalışmada yer alan kategorik veriler frekans ve yüzde ile sürekli veriler ortalama ve standart sapma ile ifade edildi. Veriler normal dağılım açısından Kolmogorov-Smirnov ve dağılım grafikleri ile incelendi. Sürekli verilerin iki grup arasında karşılaştırılmasında Mann-Whitney U testi, ikiden fazla grubun karşılaştırılmasında Kruskal-Wallis testi kullanıldı. Post-hoc analizler Bonferroni düzeltmesi kullanılarak Mann-Whitney U testi ile yapıldı. Veriler SPSS 20.0 paket programı ile analiz edildi. İstatistiksel anlamlılık düzeyi $\mathrm{p}<0,05$ olarak kabul edildi. 


\section{Bulgular}

\section{Tablo 1.}

Katılımcıların Demografik Değişkenlere İlişkin Betimsel İstatistikleri (N) ve (\%)

\begin{tabular}{|c|c|c|}
\hline & $\mathbf{n}$ & $\%$ \\
\hline \multicolumn{3}{|l|}{ Cinsiyet } \\
\hline Kadın & 34 & 28,3 \\
\hline Erkek & 86 & 71,7 \\
\hline \multicolumn{3}{|l|}{ Yaş } \\
\hline $20-25$ & 33 & 27,5 \\
\hline $26-31$ & 56 & 46,7 \\
\hline $32-37$ & 23 & 19,2 \\
\hline $38-43$ & 6 & 5,0 \\
\hline $44-49$ & 2 & 1,7 \\
\hline \multicolumn{3}{|l|}{ Eğitim Durumu } \\
\hline Lise & 33 & 27,5 \\
\hline Lisans & 70 & 58,3 \\
\hline Lisans Üstü & 17 & 14,2 \\
\hline \multicolumn{3}{|l|}{ Antrenörlük Kademesi } \\
\hline 1. Kademe & 34 & 28,3 \\
\hline 2. Kademe & 32 & 26,7 \\
\hline 3. Kademe & 41 & 34,2 \\
\hline 4. Kademe & 11 & 9,2 \\
\hline 5. Kademe & 2 & 1,7 \\
\hline \multicolumn{3}{|l|}{ Antrenörlük belgesi edinme yolu } \\
\hline Denklik (Üniversiteden) & 59 & 49,2 \\
\hline Antrenörlük Kursları & 61 & 50,8 \\
\hline \multicolumn{3}{|l|}{ Antrenörlük Deneyimi } \\
\hline $0-5$ y1l & 54 & 45,0 \\
\hline $6-10$ y1l & 42 & 35,0 \\
\hline 11 ve üzeri & 24 & 20,0 \\
\hline \multicolumn{3}{|l|}{ Antrenörlük Asıl Meslek mi? } \\
\hline Evet & 111 & 92,5 \\
\hline Hayır & 9 & 7,5 \\
\hline
\end{tabular}

Katılımcıların \%71,7'si erkek olup \%46,7'si 26-31 yaş grubundandır. Lisans mezunu katılımcı oranı \%58,3'tür. \%34,2'sinin antrenörlük kademesi 3. kademedir. \%50,8'i antrenörlük belgesini antrenörlük kursları ile edinmiştir. \%45'i 0-5 yıllık antrenörlük deneyimine sahip iken \%92,5'inin asıl mesleği antrenörlüktür. 
Tablo 2.

Voleybol Antrenörlerinin VAMYÖ Puanlarının “Cinsiyet”e Göre Mann-Whitney U Test Sonuçları

\begin{tabular}{|c|c|c|c|c|}
\hline & $\begin{array}{c}\text { Kadın } \\
\mathbf{n}=34\end{array}$ & $\begin{array}{c}\text { Erkek } \\
\mathrm{n}=86\end{array}$ & $\mathbf{U}$ & $\mathbf{p}$ \\
\hline Motivasyon Yeterliği & $1,66 \pm 0,43$ & $1,53 \pm 0,38$ & 1213,0 & 0,144 \\
\hline Teknik Öğretim Yeterliği & $1,82 \pm 0,49$ & $1,75 \pm 0,43$ & 1347,5 & 0,502 \\
\hline Kişilik Kazandırma & $1,82 \pm 0,49$ & $1,69 \pm 0,46$ & 1221,0 & 0,156 \\
\hline $\begin{array}{l}\text { Liderlik ve Takım Yönetimi } \\
\text { Yeterliği }\end{array}$ & $2,19 \pm 0,40$ & $2,35 \pm 0,41$ & 1149,5 & 0,066 \\
\hline Kondisyon ve Taktik Yeterliği & $1,88 \pm 0,48$ & $1,69 \pm 0,55$ & 1172,5 & 0,089 \\
\hline Ölçek Toplamı & $1,86 \pm 0,35$ & $1,78 \pm 0,33$ & 1250,0 & 0,216 \\
\hline
\end{tabular}

U: Mann whitney U testi

Katılımcıların Voleybol Antrenörü Mesleki Öz Yeterlik Ölçeği toplamı ve alt boyut puanlarında cinsiyete göre anlamlı fark yoktur ( $\mathrm{p}>0.05)$. Cinsiyet değişkeni, Voleybol Antrenörü Mesleki Öz Yeterlik Ölçeği puanlarını etkilememektedir.

Tablo 3.

Voleybol Antrenörlerinin VAMYÖ Puanlarının "Yaş”a Göre Kruskal Wallis Test Sonuçları

\begin{tabular}{lcccccc}
\hline & $\begin{array}{c}\mathbf{2 0 - 2 5} \\
\mathbf{n = 3 3}\end{array}$ & $\begin{array}{c}\mathbf{2 6 - 3 1} \\
\mathbf{n = 5 6}\end{array}$ & $\begin{array}{c}\mathbf{3 2 - 3 7} \\
\mathbf{n = 2 3}\end{array}$ & $\begin{array}{c}\mathbf{3 8} \text { ve üzeri } \\
\mathbf{n = 8}\end{array}$ & $\mathbf{x}^{\mathbf{2}}$ & $\mathbf{p}$ \\
\hline Motivasyon Yeterliği & $1,65 \pm 0,41$ & $1,56 \pm 0,32$ & $1,48 \pm 0,42$ & $1,48 \pm 0,70$ & 4,930 & 0,177 \\
Teknik Öğretim Yeterliği & $1,86 \pm 0,49$ & $1,76 \pm 0,36$ & $1,68 \pm 0,42$ & $1,75 \pm 0,78$ & 2,267 & 0,519 \\
Kişilik Kazandırma & $1,78 \pm 0,51$ & $1,73 \pm 0,43$ & $1,70 \pm 0,39$ & $1,60 \pm 0,78$ & 2,128 & 0,546 \\
$\begin{array}{l}\text { Liderlik ve Takım Yönetimi } \\
\text { Yeterliği }\end{array}$ & $2,23 \pm 0,47$ & $2,31 \pm 0,37$ & $2,42 \pm 0,39$ & $2,20 \pm 0,39$ & 3,219 & 0,359 \\
Kondisyon ve Taktik Yeterliği & $1,78 \pm 0,56$ & $1,76 \pm 0,49$ & $1,73 \pm 0,57$ & $1,56 \pm 0,65$ & 0,917 & 0,821 \\
& & & & & & \\
Ölçek Toplamı & $1,85 \pm 0,35$ & $1,80 \pm 0,26$ & $1,77 \pm 0,36$ & $1,70 \pm 0,61$ & 2,426 & 0,489 \\
\hline
\end{tabular}

$\mathrm{x}^{2}:$ Kruskal Wallis testi

Katılımcıların Voleybol Antrenörü Mesleki Öz Yeterlik Ölçeği toplamı ve alt boyut puanlarında yaş grubuna göre anlamlı fark yoktur $(\mathrm{p}>0.05)$. Yaş grubu, Voleybol Antrenörü Mesleki Öz Yeterlik Ölçeği puanlarını etkilememektedir. 
Tablo 4.

Voleybol Antrenörlerinin VAMYÖ Puanlarının “Eğitim Durumu”na Göre Kruskal Wallis Test Sonuçları

\begin{tabular}{lccccc}
\hline & $\begin{array}{c}\text { Lise } \\
\mathbf{n = 3 3}\end{array}$ & $\begin{array}{c}\text { Lisans } \\
\mathbf{n = 7 0}\end{array}$ & $\begin{array}{c}\text { Lisans Üstï } \\
\mathbf{n = 1 7}\end{array}$ & $\mathbf{x}^{\mathbf{2}}$ & $\mathbf{p}$ \\
\hline Motivasyon Yeterliği & $1,67 \pm 0,37$ & $1,53 \pm 0,40$ & $1,51 \pm 0,45$ & 3,699 & 0,157 \\
Teknik Öğretim Yeterliği & $1,79 \pm 0,49$ & $1,78 \pm 0,42$ & $1,70 \pm 0,46$ & 0,422 & 0,810 \\
Kişilik Kazandırma & $1,81 \pm 0,51$ & $1,72 \pm 0,45$ & $1,60 \pm 0,49$ & 2,131 & 0,345 \\
$\quad \begin{array}{l}\text { Liderlik ve Takım Yönetimi } \\
\text { Yeterliği }\end{array}$ & $2,27 \pm 0,49$ & $2,32 \pm 0,38$ & $2,31 \pm 0,36$ & 0,260 & 0,878 \\
$\quad$ Kondisyon ve Taktik Yeterliği & $1,84 \pm 0,54$ & $1,71 \pm 0,53$ & $1,70 \pm 0,57$ & 1,506 & 0,471 \\
Ölçek Toplamı & $1,86 \pm 0,33$ & $1,79 \pm 0,32$ & $1,74 \pm 0,40$ & 1,832 & 0,400 \\
$\mathbf{x}^{2}:$ Kruskal Wallis testi & & & & &
\end{tabular}

Katılımcıların Voleybol Antrenörü Mesleki Öz Yeterlik Ölçeği toplamı ve alt boyut puanlarında eğitim düzeyine göre anlamlı fark yoktur ( $p>0.05)$. Eğitim düzeyi, Voleybol Antrenörü Mesleki Öz Yeterlik Ölçeği puanlarını etkilememektedir.

Tablo 5.

Voleybol Antrenörlerinin VAMYÖ Puanlarının “Antrenörlük Kademesi”ne Göre Kruskal Wallis Test Sonuçları

\begin{tabular}{|c|c|c|c|c|c|c|c|}
\hline & $\begin{array}{c}1 . \\
\text { Kademe } \\
n=34\end{array}$ & $\begin{array}{c}2 . \\
\text { Kademe } \\
n=32\end{array}$ & $\begin{array}{c}3 . \\
\text { Kademe } \\
n=41\end{array}$ & $\begin{array}{c}\text { 4. ve } 5 . \\
\text { Kademe } \\
n=13\end{array}$ & $x^{2}$ & $\mathbf{p}$ & post-hoc \\
\hline Motivasyon Yeterliği & $1,68 \pm 0,40$ & $1,55 \pm 0,30$ & $1,54 \pm 0,47$ & $1,36 \pm 0,30$ & 7,296 & 0,063 & - \\
\hline $\begin{array}{l}\text { Teknik Öğretim } \\
\text { Yeterliği }\end{array}$ & $1,85 \pm 0,48$ & $1,81 \pm 0,33$ & $1,76 \pm 0,49$ & $1,54 \pm 0,39$ & 4,990 & 0,173 & - \\
\hline Kişilik Kazandırma & $1,81 \pm 0,49$ & $1,80 \pm 0,35$ & $1,71 \pm 0,53$ & $1,42 \pm 0,39$ & 7,849 & $0,049 *$ & $2>4$ \\
\hline $\begin{array}{l}\text { Liderlik ve Takım } \\
\text { Yönetimi Yeterliği }\end{array}$ & $2,34 \pm 0,49$ & $2,44 \pm 0,32$ & $2,25 \pm 0,38$ & $2,03 \pm 0,31$ & 11,053 & $0,011 *$ & $2>4$ \\
\hline $\begin{array}{l}\text { Kondisyon ve Taktik } \\
\text { Yeterliği }\end{array}$ & $1,87 \pm 0,54$ & $1,95 \pm 0,37$ & $1,62 \pm 0,59$ & $1,29 \pm 0,33$ & 19,016 & $<0,001 *$ & $\begin{array}{c}1,2,3>4 \\
2>3\end{array}$ \\
\hline Ölçek Toplamı & $1,89 \pm 0,34$ & $1,88 \pm 0,17$ & $1,76 \pm 0,39$ & $1,51 \pm 0,22$ & 19,832 & $<0,001 *$ & $1,2,3>4$ \\
\hline
\end{tabular}

Katılımcıların Voleybol Antrenörü Mesleki Öz Yeterlik Ölçeği puanlarında antrenörlük kademesine göre anlamlı fark görülmüştür $(p<0.05)$. 
Farkın hangi gruptan kaynaklandığına yönelik yapılan post-hoc analizde "Kişilik kazandırma" alt boyutunda 2. Kademe voleybol antrenörlerinin puanının 4. ve 5. Kademe antrenörlerden anlamlı derecede yüksek olduğu görülmüştür $(\mathrm{p}<0.05)$. Benzer şekilde "Liderlik ve Takım Yönetimi Yeterliğgi" alt boyutunda da 2. Kademe voleybol antrenörlerinin puan1 4. ve 5. Kademe antrenörlerden anlamlı derecede yüksektir ( $\mathrm{p}<0.05)$.

"Kondisyon ve Taktik Yeterliğii" alt boyutunda 4. ve 5. Kademe antrenörlerin puanı diğer kademelerden anlamlı derecede düşüktür $(\mathrm{p}<0.05)$. 2. Kademe antrenörlerin puanı 3 . kademeden anlamlı derecede yüksektir $(\mathrm{p}<0.05)$.

Voleybol Antrenörü Mesleki Öz Yeterlik Ölçeği toplam puanına bakıldığında, 4. ve 5. Kademe antrenörlerin puanının diğer kademelerden anlamlı derecede düşük olduğu görülmüştür $(\mathrm{p}<0.05)$.

Tablo 6.

Voleybol Antrenörlerinin VAMYÖ Puanlarının “Antrenörlük Belgesi Edinme Yolu”na Göre MannWhitney U Testi Sonuçları

\begin{tabular}{lcccc}
\hline & $\begin{array}{c}\text { Denklik } \\
\text { (Üniversiteden) } \\
\mathbf{n = 5 9}\end{array}$ & $\begin{array}{c}\text { Antrenörlük } \\
\text { Kursları } \\
\mathbf{n = 6 1}\end{array}$ & $\mathbf{U}$ & $\mathbf{p}$ \\
\hline Motivasyon Yeterliği & $1,56 \pm 0,32$ & $1,57 \pm 0,47$ & 1074,0 & 0,655 \\
Teknik Öğretim Yeterliği & $1,81 \pm 0,35$ & $1,74 \pm 0,52$ & 1057,0 & 0,567 \\
Kişilik Kazandırma & $1,73 \pm 0,40$ & $1,73 \pm 0,54$ & 1096,0 & 0,777 \\
$\begin{array}{l}\text { Liderlik ve Takım Yönetimi } \\
\text { Yeterliği }\end{array}$ & $2,38 \pm 0,36$ & $2,23 \pm 0,44$ & 925,0 & 0,119 \\
Kondisyon ve Taktik Yeterliği & $1,79 \pm 0,46$ & $1,70 \pm 0,60$ & 977,5 & 0,243 \\
Ölçek Toplamı & $1,83 \pm 0,26$ & $1,77 \pm 0,39$ & 1066,0 & 0,615 \\
\hline
\end{tabular}

Katılımcıların Voleybol Antrenörü Mesleki Öz Yeterlik Ölçeği toplamı ve alt boyut puanlarında antrenörlük belgesi edinme yoluna göre anlamlı fark yoktur $(p>0.05)$. Antrenörlük belgesini denklik yoluyla alanlar ile antrenörlük kursları ile edinenler arasında ölçek puanları benzer düzeydedir. 
Tablo 7.

Voleybol Antrenörlerinin VAMYÖ Puanlarının “Antrenörlük Deneyimi”ne Göre Kruskal Wallis Test Sonuçları

\begin{tabular}{|c|c|c|c|c|c|}
\hline & $\begin{array}{c}0-5 \text { yll } \\
\mathrm{n}=54\end{array}$ & $\begin{array}{l}6-10 \text { yil } \\
n=42 \text { yll }\end{array}$ & $\begin{array}{c}11 \text { ve üzeri } \\
n=24\end{array}$ & $\mathbf{x}^{2}$ & $\mathbf{p}$ \\
\hline Motivasyon Yeterliği & $1,58 \pm 0,41$ & $1,53 \pm 0,32$ & $1,60 \pm 0,50$ & 0,192 & 0,909 \\
\hline Teknik Öğretim Yeterliği & $1,79 \pm 0,45$ & $1,72 \pm 0,38$ & $1,83 \pm 0,54$ & 1,032 & 0,597 \\
\hline Kişilik Kazandırma & $1,73 \pm 0,48$ & $1,72 \pm 0,43$ & $1,75 \pm 0,55$ & 0,100 & 0,951 \\
\hline $\begin{array}{l}\text { Liderlik ve Takım Yönetimi } \\
\text { Yeterliği }\end{array}$ & $2,23 \pm 0,42$ & $2,36 \pm 0,38$ & $2,37 \pm 0,40$ & 3,108 & 0,211 \\
\hline Kondisyon ve Taktik Yeterliği & $1,68 \pm 0,59$ & $1,79 \pm 0,43$ & $1,83 \pm 0,58$ & 1,902 & 0,386 \\
\hline Ölçek Toplamı & $1,78 \pm 0,33$ & $1,80 \pm 0,24$ & $1,85 \pm 0,45$ & 1,212 & 0,546 \\
\hline
\end{tabular}

$\mathrm{x}^{2}:$ Kruskal Wallis testi

Katılımcıların Voleybol Antrenörü Mesleki Öz Yeterlik Ölçeği toplamı ve alt boyut puanlarında antrenörlük deneyimine göre anlamlı fark yoktur ( $>0.05)$. Antrenörlük deneyimi, Voleybol Antrenörü Mesleki Öz Yeterlik Ölçeğinden alınan puanları etkilememektedir.

Tablo 8.

Voleybol Antrenörlerinin VAMYÖ Puanlarının "Mesleki Durumu”na Göre Mann-Whitney U Testi Sonuçları

\begin{tabular}{|c|c|c|c|c|}
\hline & \multicolumn{2}{|c|}{ Antrenörlük asıl mesleğiniz mi? } & \multirow[b]{2}{*}{$\mathbf{U}$} & \multirow[b]{2}{*}{$\mathbf{p}$} \\
\hline & $\begin{array}{c}\text { Evet } \\
\text { n=111 }\end{array}$ & $\begin{array}{c}\text { Hayır } \\
\mathrm{n}=9\end{array}$ & & \\
\hline Motivasyon Yeterliği & $1,57 \pm 0,39$ & $1,52 \pm 0,58$ & 437,0 & 0,531 \\
\hline Teknik Öğretim Yeterliği & $1,80 \pm 0,43$ & $1,44 \pm 0,48$ & 281,0 & $\mathbf{0 , 0 2 8 *}$ \\
\hline Kişilik Kazandırma & $1,75 \pm 0,46$ & $1,47 \pm 0,59$ & 326,5 & 0,082 \\
\hline $\begin{array}{l}\text { Liderlik ve Takım Yönetimi } \\
\text { Yeterliği }\end{array}$ & $2,32 \pm 0,40$ & $2,11 \pm 0,52$ & 362,0 & 0,166 \\
\hline $\begin{array}{l}\text { Kondisyon ve Taktik } \\
\text { Yeterliği }\end{array}$ & $1,77 \pm 0,53$ & $1,46 \pm 0,61$ & 349,0 & 0,130 \\
\hline Ölçek Toplamı & $1,82 \pm 0,32$ & $1,59 \pm 0,42$ & 329,0 & 0,089 \\
\hline
\end{tabular}

Katılımcıların Voleybol Antrenörü Mesleki Öz Yeterlik Ölçeğinin “Teknik Öğretim Yeterliği” alt boyut puanlarında mesleki duruma göre anlamlı fark görülmüştür $(p<0.05)$. Antrenörlük asıl mesleği olan katılımcıların puanı istatistiksel açıdan anlamlı derecede yüksektir.

Ölçek toplamında ve diğer alt boyutlarda alınan puanlar mesleki duruma göre farklılaşmamaktadır $(\mathrm{p}<0.05)$. 


\section{Tartıșma ve Sonuç}

$\mathrm{Bu}$ araştırmanın konusu voleybol antrenörlerinin kendi antrenörlük yeterliklerine inançlarının incelenmesidir.

Araştırmanın birinci hipotezi (H1) ile ilgili analiz sonuçlarına göre, cinsiyet değişkeni, Voleybol Antrenörü Mesleki Öz Yeterlik Ölçeği puanlarını etkilememektedir. Seçkin Ağırbaş vd. (2020)' nin, kamu ve özel kurumlarda ya da kulüplerde aktif olarak görev yapan 283 antrenör üzerinde yaptıkları araştırmada, erkek antrenörlerin kadın antrenörlere göre öz yeterlik değerlerinin düşük seviyede olduğunu belirlemişlerdir. Kavussanu, Boardley, Jutkiewicz, Vincent and Ring (2006) ise, erkek antrenörlerin kadın antrenörlere kıyasla, antrenörlük yapma ve takımlarını başarıya ulaştırma konusundaki yeteneklerine daha fazla inandıklarını öne sürmüşlerdir. Koçak (2019), antrenörlerin öz yeterlik düzeylerinde cinsiyete göre anlamlı bir farklılık olmadığını bulmuştur. Huang, (2006), Tayvan’ daki okullarda görev yapan 332 voleybol antrenörü üzerinde yaptı̆̆ araştırmasında antrenörlük yeterliği açısından erkek ve kadın arasında anlamlı bir fark olmadığını ileri sürmüştür. Literatürde benzer sonuçlara ulaşan başka araştırmalarda mevcuttur (Sullivan ve Kent, 2003).

Araştırmanın ikinci hipotezi (H2) ile ilgili analiz sonuçlarına göre, katılımcıların Voleybol Antrenörü Mesleki Öz Yeterlik Ölçeği toplamı ve alt boyut puanlarında yaş grubuna göre anlamlı fark bulunmamıştır. Seçkin Ağırbaş vd. (2020) tarafından yapılan araştırmada, öz yeterlik seviyesinin yaş grubu değişkenine göre farklılaşmadığı sonucu ortaya çıkmıştır. Aynı şekilde Koçak (2019)' un araştırma sonuçları da antrenörlerin öz yeterlik düzeylerinde yaşa göre anlamlı bir farklılık olmadığını göstermektedir. Kowalski (2007), futbol antrenörleri üzerinde yaptığı çalışmasının sonuçlarına göre yaş değişkeninin antrenörlerin öz yeterliğine bir etkisinin olmadığını ifade etmiştir. Literatürdeki araştırmaların sonuçları ile araştırmamızın sonuçlarının yaş değişkeni açısından paralellik gösterdiği söylenebilir.

Araştırmanın üçüncü hipotezi (H3) ile ilgili analiz sonuçları doğrultusunda eğitim düzeyinin, Voleybol Antrenörü Mesleki Öz Yeterlik Ölçeği puanlarını etkilemediği ortaya çıkmıştır. Aynı şekilde Çik (2019)' de, antrenör öz yeterliğinin, antrenörlerin eğitim düzeylerine göre farklılaşmadığ sonucuna ulaşmıştır.

Araştırmanın dördüncü hipotezi (H4) ile ilgili analiz sonuçlarına göre, voleybol antrenörlerinin antrenörlük kademesine göre mesleki öz yeterliğinin tüm alt boyutlarda istatistiksel olarak anlamlı düzeyde farklılaştığı görülmektedir.Buna göre "Kişilik kazandırma" ve "Liderlik ve Takım Yönetimi Yeterliği” alt boyutlarında 2. Kademe voleybol antrenörlerinin puanının 4. ve 5. Kademe antrenörlerden anlamlı derecede yüksek olduğu görülmüştür. "Kondisyon ve Taktik Yeterliğii” alt boyutunda 4. ve 5. Kademe antrenörlerin puanı diğer kademelerden anlamlı derecede 
düşüktür. 2. Kademe antrenörlerin puanı 3. kademeden anlamlı derecede yüksektir.Voleybol Antrenörü Mesleki Öz Yeterlik Ölçeği toplam puanına bakıldığında, 4. ve 5. Kademe antrenörlerin puanının diğer kademelerden anlamlı derecede düşük olduğu görülmüştür. Seçkin Ağırbaş vd. (2020) antrenörlerin öz yeterlik düzeylerini incelediği araştırmasında, antrenörlük kademesine göre öz yeterlik düzeylerinde anlamlı bir farklılığa rastlamamışlardır. Benzer sonuçlara Toklu (2010) ve Çik (2019)' da ulaşmıştır. Ermiş, Satıcı, Bostancı, İmamoğlu ve Taşmektepligil (2019), tenis antrenörlerinin yeterlik düzeyini araştırdıkları çalışmada ise, antrenörlerin antrenörlük kademelerine göre, benzer şekilde anlamlı farklılık tespit etmişlerdir. Ancak bu sonuca göre antrenörlerin kademeleri ile öz yeterlik seviyeleri doğru orantılı bir şekilde artmaktadır. Başka bir çalışmada da 1. ve 3. Kademe antrenörlerin öz yeterlik düzeylerinde anlamlı bir fark bulunmuş ve katılımcıların antrenörlük kademesi düştükçe öz yeterlik düzeyinde de düşüş görülmüştür (Köksal, 2008). Malete ve Feltz (2000), antrenör eğitim modüllerini alan antrenörlerin, almayan antrenörlere göre antrenör öz yeterliklerini incelediği çalışmalarında, eğitim alan antrenörlerin lehine anlamlı bir farklılığa rastlamışlardır. Bu sonuçlar araştırmamızın sonuçlarıyla çelişmektedir. Araştırmamızdaki sonuçlar antrenörlerin mesleki bilgi ve becerilerinin artmasının yanında mesleki deneyimlerinin de artması ile mesleki olgunluğa erişmeleri ve öğreneceklerinin sınırının olmadığını farketmeleri sonucunda ortaya çıkmış olabilir. Voleybol antrenörlerin görevlerine yönelik mükemmeliyetçi yaklaşımları da bu sonucu doğurmuş olabilir.

Araştırmanın beşinci hipotezi (H5) ile ilgili analiz sonuçlarına göre, katılımcıların Voleybol Antrenörü Mesleki Öz Yeterlik Ölçeği toplamı ve alt boyut puanlarında antrenörlük belgesi edinme yoluna göre anlamlı farka rastlanmamıştır. Antrenörlük belgesini denklik yoluyla alanlar ile antrenörlük kursları ile edinenler arasında ölçek puanları benzer düzeydedir. Literatürde bu sonucu tartışacak herhangi bir çalışmaya rastlanmamıştır. Bu sonuç gelecek araştırmalar için kaynak niteliğindedir.

Araştırmanın altıncı hipotezi (H6) ile ilgili analiz sonuçlarına göre, antrenörlük deneyimi, Voleybol Antrenörü Mesleki Öz Yeterlik Ölçeğinden alınan puanları etkilememektedir. Huang, (2006), yaptığı araştırmanın bulgularına göre antrenörlük deneyimi fazla olan antrenörlerin , antrenörlük deneyimi az olanlara göre daha fazla mesleki öz yeterlik özelliği gösterdiği ortaya çıkmıştır. Antrenör yeterliği kişinin geçmiş performans ve deneyimlerinden etkilenmektedir (Feltz ve diğerleri, 1999). Kavussanu ve diğerlerinin (2006), İngiliz üniversite takımlarında görev yapan 26 antrenör üzerinde yaptıkları çalışmada, artan antrenörlük deneyiminin sporculardaki teknik eksikliklerin tespit edilmesi ve giderilmesi için önemli olduğu sonucu ortaya çıkmıştır.

Araştırmanın yedinci hipotezi (H7) ile ilgili analiz sonuçlarına göre, katılımcıların Voleybol Antrenörü Mesleki Öz Yeterlik Ölçeğinin “Teknik Öğretim Yeterliği” alt boyut puanlarında mesleki duruma göre anlamlı fark görülmüştür. Antrenörlük asıl mesleği olan katılımcıların puanı istatistiksel 
açıdan anlamlı derecede yüksektir. Ölçek toplamında ve diğer alt boyutlarda alınan puanlar mesleki duruma göre farklılaşmamaktadır. Demir ve Kabakçı (2020), kano antrenörlerinin öz yeterliklerini araştırdıkları çalışmada, mesleki durum değişkenine göre anlamlı bir fark bulamamıştır.

Sonuç olarak elde edilen bulgulara göre, antrenörlük kademesinin mesleki öz yeterlik düzeyinin önemli bir belirleyicisi olduğu sonucuna ulaşılmıştır. Cinsiyet, yaş, eğitim düzeyi, antrenör belgesi edinme yolu, antrenörlük deneyimi ve mesleki durumu değişkenlerinin ise bu araştırma örnekleminde mesleki öz yeterlik düzeyinin bir belirleyicisi olmadıkları görülmüştür. Bu sonuçlarla, araştırmanın hipotezlerinden sadece $\mathrm{H} 4$ kabul edilmiş, H1, H2, H3, H5, H6 ve H7 hipotezleri red edilmiştir.

Bazı araştırmacılar, antrenörlük yetenekleri konusunda yüksek öz yeterliğe sahip antrenörlerin, sporcularının performansını artırmaya yönelik onları daha fazla motive ettiğini ve geliştirdiğini vurgulamıştır (Feltz ve diğerleri, 1999; Moritz vd., 2000). Bu antrenörler genellikle yeni fikirlere daha açık ve yeni yöntemler denemeye hazırdır. Antrenörlüğün yanı sıra kişisel eğitime ve gelişime bağlıdırlar (Feltz vd., 2008; akt. Mesquita vd, 2012).

$\mathrm{Bu}$ çalışma, her ne kadar kapsamlı bir ölçek vasıtasıyla antrenörlerin öz-yeterlik algılarına ilişkin temsili bir portre sunsa da, antrenör algılarının ve davranışlarının kendine özgü doğasını kaybetmemek için niteliksel olarakda araştırılması gerekir. Bu konuyu derinlemesine anlamak ve olası sorunları keşfetmek için daha fazla nitel araştırmalara ihtiyaç vardır.

Araştırma daha geniş örneklem grubuna uygulanırsa daha geçerli kanıtlar sunulabilir.

Araştırmacılar, antrenörlerin mesleki öz yeterliklerine ilişkin gelecek araştırmalarda uluslararası karşılaştırmalarla ilgilenebilir.

\section{Kaynaklar}

Bandura, A. (2012). On the functional properties of perceived self-efficacy revisited. Journal of Management, 38(1), 9-44. doi:10.1177/0149206311410606

Çik, B. (2019). Sporcular tarafindan algılanan antrenör davranışlarının antrenörlerin yeterliğiyle ilişkisinin incelenmesi. Yayınlanmamış yüksek lisans tezi, Marmara Üniversitesi, Sağlık Bilimleri Enstitüsü, İstanbul.

Demers, G., Woodburn, A., \& Savard, C. (2006). The development of an undergraduate competency based coach education program. The Sport Psychologist, 20(2), 162-173.

Demir, A. ve Kabakçı, A.C. (2020). Kano antrenörlerinin psikolojik sağlamlıkları, algılanan öz-yeterlikleri ve yaşam doyumu arasındaki ilişkinin incelenmesi. International Journal of Exercise Psychology, 2(1), 21-28.

Duffy, P. (2008). Implementation of the Bologna process and model curriculum development in coaching. In K. Petry, K. Froberg, A. Madella, \& W. Tokarsky (Eds.), Higher Education in Sport in Europe. From labour market demand to training supply (pp. 80-108). Aachen: Meyer \& Meyer Sport.

Ermiş, E., Satıcı, A., Bostancı, Ö., İmamoğlu, O. ve Taşmektepligil, M.Y. (2019). Tenis Antrenörleri yeterlik düzeyinin araştırılması. OPUS-Uluslararası Toplum Araştırmaları Dergisi, 9(14), 1211-1227. doi: 10.26466/ opus.605062

Feltz, D., Chase, M., Moritz, S., \& Sullivan, P. (1999). A conceptual model of coaching efficacy: Preliminary investigation and instrument development. Journal of Educational Psychology, 91(4), 765-776. 
Hoyt, C., Murphy, S., Halverson, S. and Watson C. (2003). Group leadership: Efficacy and effectiveness. Group Dynamics: Theory, Research, and Practice 7, 259-274.

Huang, Y.C. (2006). The relationships among job satisfaction, perefessional commitment, organizational alienation and coaching efficacy of school volleyball coaches in Taiwan. United States Sport Academy, USA: ProQuest Dissetations Publishing.

Kavussanu, M., Boardley, I.D., Jutkiewicz, N., Vincent, S. \& Ring, C. (2008). Coaching efficacy and coaching effectiveness: Examining their predictors and comparing coaches' and athletes' reports. The Sport Psychologist, 22, 383-404.

Klassen, R. M., Tze, V. M. C., Betts, S. M., \& Gordon, K. A. (2011). Teacher efficacy research 1998-2009: Signs of progress or unfulfilled promise? Educational Psychology Review, 23(1), 21-43. doi:10.1007/s10648-0109141-8

Koçak, Ç.V. (2019). Antrenör adaylarının antrenör öz-yeterlik düzeylerinin incelenmesi. SPORMETRE Beden Eğitimi ve Spor Bilimleri Dergisi, 17(1), 55-66. doi: 10.33689/spormetre.520507

Koçak, Ç. V. ve Güven, Ö. (2018). Voleybol antrenörü mesleki öz yeterlik ölçeği geçerlik ve güvenirlik çalışması. SPORMETRE Beden Eğitimi ve Spor Bilimleri Dergisi, 16 (2), 162-177.

Kowalski, C.L. (2007). An analysis of coaching efficacy in volunteer soccer coaches. Master Thesis, North Iowa University. U.S.A.

Köksal F. (2008) . Antrenörlerin liderlik tarzları ile öz-yeterlilikleri arasındaki ilişki. Yayınlanmamış yüksek lisans tezi, Selçuk Üniversitesi, Sağlık Bilimleri Enstitüsü, Konya.

Luszczynska, A., Gutierrez-Dona, B. \& Schwarzer, R. (2005). General self-efficacy in various domains of human functioning: Evidence from five countries. International Journal of Psychology, 40(2), 80-89. doi:10.1080/00207590444000041

Malete, L. \& Feltz, D. L. (2000). The effect of a coaching education program on coaching efficacy. The Sport Psychologist, 14(4), 410-417.

Mesquita, I., Borges, M., Rosado, A. \& Batista, P.M. (2012). Self-efficacy, perceived training needs and coaching competences: The case of Portuguese handball. European Journal of Sport Science, 12(2), 168-178. doi: 10.1080/17461391.2010.551413

Moritz, S. E., Feltz, D. L., Fahrbach, K. R., \& Mack, D. E. (2000). The relation of self-efficacy measures to sport performance: A meta-analytic review. Research Quarterly for Exercise and Sport, 71(3), 280-294.

Pajares, F. (2002). Overview of social cognitive theory and of self-efficacy. Erişim tarihi: 06.05.2021 http://www.emory.edu/EDUCATION/mfp/eff.html

Papastergiou, M. (2010). Enhancing physical education and sport science students' self-efficacy and attitudes regarding information and communication technologies through a computer literacy course. Computer\&Education, 54, 298-308. doi: 10.1016/j.compedu.2009.08.015

Seçkin Ağırbaş, İ., Erel, S. ve Belli, E. (2020). Antrenörlerin öz yeterlilikleri ile iletişim becerileri ilişkisi. Anatolia Sport Research, 1(1), 25-36.

Sullivan, P.J., \& Kent, A. (2003). Coaching efficacy as a predictor of leadership style in intercollegiate athletics. Journal of Applied Sport Psychology, 15, 1-11.

Tojjari, F., Esmaelli, M.R. \& Bavandpour, R. (2013). The effect of self-efficacy on job satisfaction of sport referees. European Journal of Experimental Biology, 3(2), 219-225.

Toklu O. (2010). Tenis antrenörlerinde liderlik özellikleri ve öz yeterlilik arasındaki ilişkinin belirlenmesi. Yayınlanmamış yüksek lisans tezi, Selçuk Üniversitesi, Sağlık Bilimleri Enstitüsü, Spor Yöneticiliği Ana Bilim Dal, Konya.

Usher, E. L., \& Pajares, F. (2009). Sources of self-efficacy in mathematics: A validation study. Contemporary Educational Psychology, 34(1), 89-101. doi:10.1016/j.cedpsych.2008.09.002 